\title{
The importance of food retail stores in identifying food deserts in urban settings
}

\author{
A. Behjat ${ }^{1}$, M. Koc ${ }^{2}$ \& A. Ostry ${ }^{1}$ \\ ${ }^{1}$ Geography Department, University of Victoria, Canada \\ ${ }^{2}$ Sociology Department, Ryerson University, Canada
}

\begin{abstract}
While food deserts in urban places have been fairly well studied in North America and Europe, there is little consensus on the best conceptual and operational definition for food deserts. In most of these studies researchers concentrate on mainstream grocery stores and supermarkets as the only sources of healthy and affordable food options especially in cities with diverse ethnic population. The purpose of this study is to expand this usual approach to food desert studies by investigating the inclusion of ethnic food stores and specialty stores as sources of healthy food options in a multi-ethinic Toronto neighbourhood. The Englemount-Lawrence neighbourhood was selected for this study as it has been identified as a food desert in previous studies in Toronto. An in-store survey was conducted in order to identify ethnic and specialty stores which supply healthy and affordable food options based on US Department of Agriculture dietary guidelines. Using Geographic Information System (GIS) analysis, all qualified ethnic food stores in the study area were geocoded into a neighbourhood map and a buffer of $1000 \mathrm{~m}$ was drawn around each. We found out that ethnic food stores supplying healthy and culturally-accepted food options are evenly dispersed across the Englemount-Lawrence neighbourhood. We conclude that, unlike in previous studies, this neighbourhood is not a food desert. Furthermore, failure to use an inclusive set of healthy food stores and culturally acceptable food choices, in neighbourhood studies of food deserts can significantly alter the results in the study area and hence mislead food planners and policymakers in decision-making.

Keywords: food desert, food availability, ethnic food stores, EnglemountLawrence neighbourhood.
\end{abstract}




\section{Introduction}

People need food in order to get the essential nutrients and necessary energy to carry out their daily activities. Unfortunately, due to the uneven distribution of healthy food outlets and physical, financial and social barriers, not all neighbourhoods have equal access to nutritious and affordable foods. An area where residents have limited access to healthy and affordable foods is called a 'Food Desert' [1]. Rose et al. [2] argues that food deserts is a useful concept for investigating geographic access to healthy food and for identifying areas of poor access, which helps policy-makers to improve food security. Similarly, Thomas [3] posits the concept of a food desert as a powerful tool for identifying the spatial distribution of food insecurity within communities. In these areas residents usually obtain food through fast-food outlets and higher-priced convenience stores which mostly supply unhealthy and 'junk' foods [4].

\subsection{The origin and definitions of food desert}

In the past two decades, the concept of food desert has attracted the attention of urban researchers interested in understanding the causes and consequences of neighbourhoods with limited access to food. The first use of the term 'food desert' was attributed to residents of a public sector housing scheme in the West of Scotland in the early 1990s [5]. It was picked up and used by the Policy Working Group of the UK Government's Low Income Project Team of the Nutrition Task Force in 1995 [6]. In North America, Blanchard first used the term "food deserts" in order to describe rural areas of Mississippi that were outside supermarket service areas [7]. Since then, the term has been used from different perspectives by scholars, depending on the nature of the study in urban and rural areas. For instance, Hendrickson et al. [8], defined food deserts as "urban areas with 10 or fewer stores and no stores with more than 20 employees". Gallagher [9] defined food deserts as "large geographic areas that have no or distant mainstream grocery stores”. In another study, large geographic areas where mainstream grocery stores are scarce or missing were identified as food deserts [10]. According to the US Department of Agriculture, a food desert is a low-income census tract where a substantial number or share of residents has poor access to a supermarket or large grocery store [11].

While there is little consensus on the definition of food deserts, most researchers agree on using certain general characteristics in defining a food desert such 'poor or limited access', 'few healthy food stores', 'underserved areas', 'lack of healthy food', and 'low-income residents'.

Based on the operational definition of food deserts, availability of healthy food sources in a certain area is one of the most crucial key elements in identifying that area as a food desert [4, 12, 13]. It highly depends on the inclusion and determination of the healthy food stores in that area although other food desert elements such as food accessibility and socio-economic variables can impact on food desert results. 


\subsection{Measuring food availability}

In a given food environment different types of food stores, regardless of their size, supply a wide variety of healthy and unhealthy food options. In most food desert studies, mainstream supermarkets and grocery stores are used as proxies for healthy food suppliers and small ethnic and other retail food stores are often ignored. According to Mednath [14], a "major critique of identifying food deserts is that their measurement can be misleading as areas that are categorized as food deserts that indeed may have more healthy food options than the current classification schema depicts”. Margheim [15] mentioned that grocery stores and supermarkets are not always the only providers of healthy food options in neighbourhoods. He added that ethnic food stores or small stores that specialize in meats, seafood, or fruits and vegetables might fill gaps in household food needs. Bitler and Haider [16] went even further and pointed out that the quality of fresh produce available in small food stores is better when compared with healthy food options in supermarkets. Ver Ploeg [17] argued that a focus only on supermarkets and grocery stores is likely to underestimate the availability of healthy food options since some of these healthy foods are also available at other food stores such as ethnic stores, specialty stores and farmers' markets. There is also the issue that in multi-ethnic neighbourhoods many people will prefer to go to local ethnic stores rather than big supermarkets.

In some, but not most studies, small food retailers were included as alternative sources of healthy food options in identifying food deserts. Short et al. [18] in a study of food deserts in low-income neighbourhood in San Francisco found many small well-dispersed food retailers supplying wide variety of healthy and culturally acceptable foods at relatively low prices. In a similar study, Rose et al. [2] found that some neighbourhoods (e.g., Village de L'Est, Treme in New Orleans) characterized in other studies as food deserts mainly they lacked supermarkets in fact, were not because they had many small food retailers offering basic healthy food options to residents.

Because few studies have focused on the availability of healthy food options in small food retail stores such as ethnic food stores and specialty stores in urban areas, the purpose of this study is to expand beyond the usual approach to food desert studies by investigating the inclusion of food retail stores as alternative sources of healthy food options in a multi-ethinic Toronto neighbourhood.

\section{Data and methods}

\subsection{Study area}

The City of Toronto Neighbourhood Action Plan [19] designated 13 Prioritydisadvantaged neighbourhoods where poverty is rising based on socioeconomic and demographic factors (e.g., population, employment, income, and vulnerable groups) which were extracted from the Canada Census 2006 and the city's 2007 Employment Survey. In a similar study, Chen [20] used socioeconomic variables such as income, immigration status, car ownership, education to identify 
disadvantaged neighbourhoods. Englemount-Lawrence area is one of the Toronto neighbourhoods which was classified as disadvantaged in both studies. Moreover, previous food desert studies conducted in Toronto, focused on identifying and assessing healthy food choices in large supermarkets [20, 21], a large portion of the Englemount-Lawrence neighbourhood was identified as a food desert. We re-studied this area using new methods to which also identified and estimated healthy food choices in both specialty and ethnic food stores and which excluded food retail outlets selling expensive foods as we wanted to determine the extent to which this neighbourhood was a food desert for low income residents.

The Canada Census 2006 provided a socio-demographic profile of this neighborhood. The total population of the study area is 21,115 . There is racial and ethnic diversity in the neighborhood. Twenty five percent of the population identifies as Jewish and $12 \%$ identifies as Filipino, the top two ethnic groups in the neighbourhood. Even in this relatively small neighbourhood, a significant amount of economic differentiation is evident. In particular, populations in the southern part of the neighborhood tend to have significantly higher incomes than populations in the northern area. The median household income before-tax is Can\$ 45,060 in the neighbourhood [22].

\subsection{Food store data}

In most food desert studies in the City of Toronto [4, 20, 21] the availability of healthy and affordable food options was approximated using the supermarkets and grocery stores category as defined in the North American Industry Classification System (NAICS) [23] as follows:

Supermarkets and grocery stores, which are primarily engaged in retailing a general line of food, such as canned, dry and frozen foods; fresh fruits and vegetables; fresh and prepared meats; fish, poultry, dairy products, baked products and snack foods.

In our study we also included "specialty food stores" defined according to the NAICS as:

Specialty food stores, which primarily engaged in retailing specialized lines of food products (e.g., meat, fish and seafood, fruit and vegetable markets).

It should be noted that for the first classification (supermarkets and grocery stores), based on Chen's [20] food desert study in the Greater Toronto Area (GTA), we only included discount supermarket chains (No Frills, Food Basics, and Price Chopper) which provide healthy food options at competitive prices. A specialty store was defined as a food store which sells at least one of the items such as meat, fish and seafood, fruit and vegetable markets, according to the NAICS classification. Bakeries were not included in this study, as they do not sell healthy items according to the USDA definition for healthy food items. Moreover, due to the lack of a clear definition for ethnic stores as one of the important sources of healthy food options across food desert literature, this study adopted and modified the definition, from Crouch's [24] study, as any type of non-chain grocery store or supermarket which sells food items that are distinctly 
cultural, often catering to specific segments of the immigrant population, and whose signage is in a language other than English.

Based on the US Department of Agriculture's 2010 Dietary Guidelines for Americans [25], an in-store survey was conducted in order to verify the qualified ethnic stores which supply healthy and affordable food options. Food categories included fruits, vegetables, meat group (e.g., meat, poultry, fish, eggs, and nuts), milk group (e.g., milk, yogurt, cheese, and milk-based desserts), and grains (e.g., whole grains and refined grains).

\subsection{Data preparation for food stores}

As the study area was the Englemount-Lawrence neighbourhood, it was essential to the analysis that, in order to minimize edge effects (failing to address nearby food stores outside the neighbourhood boundary that would likely cause inaccuracies in measuring food availability), submit a comprehensive picture of the study area food environment and for the sake of comparison, all food stores located 1000 metres beyond the neighbourhood boundaries were also included as possible sources of healthy food options for residents of Englemount-Lawrence neighbourhood. Food store (discount supermarkets, specialty stores, and ethnic stores) addresses and signs were gathered through field survey and on-site direct observation as the study area was small (see Appendix B). All food store addresses were geocoded within GIS (ArcGIS 10, ESRI). Geocoding is the process of matching raw address information (e.g., household, food stores) with a digital spatial dataset that includes all addresses within the area of interest mapped to latitude and longitude coordinates [26].

\subsection{Food access and identifying food deserts}

Determining the threshold for poor access to food stores that provide healthy food options is one of the essential elements of the operational definition of food deserts developed for this study. Poor access for neighbourhood residents in this study is defined as a location outside a reasonable walking distance to a food store. In almost all Canadian studies [4, 13, 27] and especially those in the City of Toronto, a distance of 1000 metres was determined as a reasonable walking distance $[20,21]$. Therefore, in order to compare the results with Toronto studies, a 1000 metre distance was used as a reasonable walking distance for neighborhood residents to reach food stores. In order to measure accessibility, ArcGIS 10.0 and the circular buffering technique was used to create a 'service area' of 1000 metres around each food store based on CanMap Streetfiles from DMTI (Desktop Mapping Technologies Incorporated) [28].

In order to clarify the discrepancies in food desert analysis, the results based on the developed operational definition of food desert in this study will be compared with previous food desert studies operational definition for Englemount-Lawrence neighbourhood. The developed operational definitions of a food desert in this study and previous studies with focus on food availability for the Englemount-Lawrence neighbourhood are as follows: 
Previous studies: Disadvantaged areas where residents are located outside a 1000 metre circular buffer zone (service area) of discount supermarkets.

This study: Disadvantaged areas where residents are located outside a 1000 metre circular buffer zone (service area) of discount supermarkets, ethnic stores and specialty stores.

As the study area (Englemount-Lawrence neighbourhood) has already been classified as a disadvantaged neighbourhood, therefore, areas outside the food store (discount supermarket chains, ethnic stores, and specialty stores) service area will be identified as food deserts in this study.

\section{Results and discussion}

The map of food desert results based on previous studies operational definition with respect to edge effect is shown in Figure 1.

According to the food desert analysis in Figure 1, a large portion of the Englemount-Lawrence neighbourhood area was identified as a food desert.

In this study, an in-store survey was conducted in order to determine the ethnic stores and specialty stores and availability of healthy food options in them

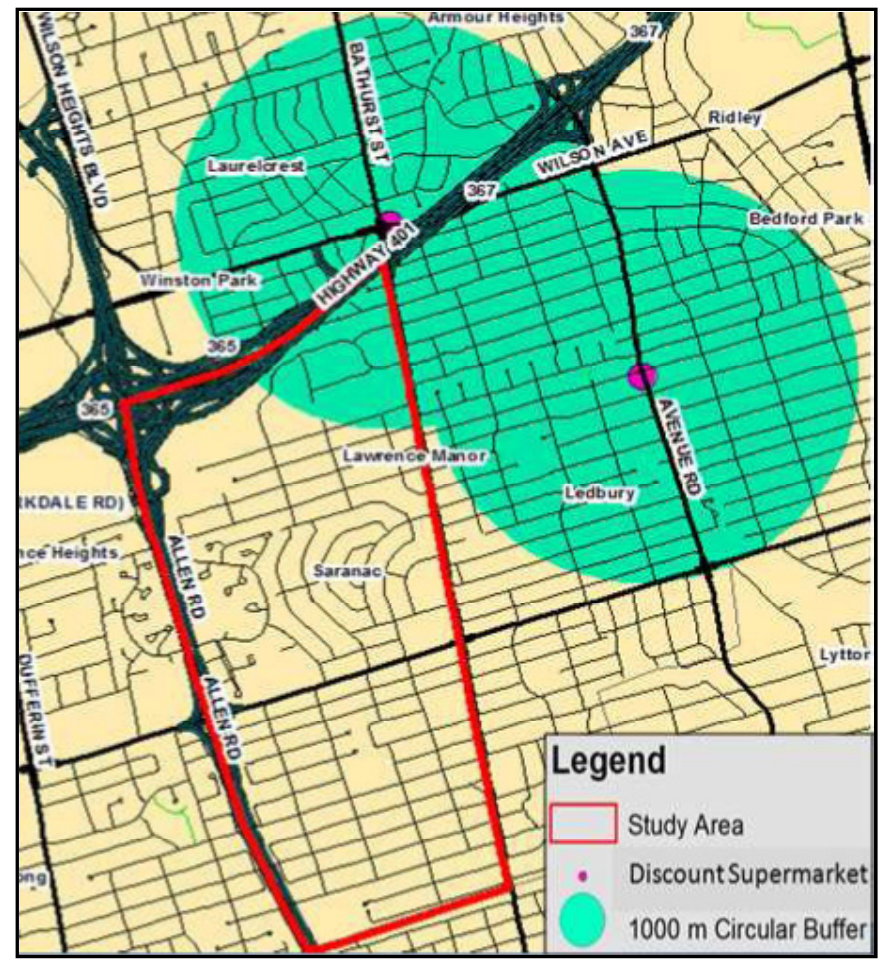

Figure 1: Map of food deserts in study area based on previous studies operational definition. 
Table 1: $\quad$ Frequency and type food retailers in the study area.

\begin{tabular}{|c|c|c|}
\hline Type of retail store & Frequency & USDA Dietary Guideline \\
\hline Ethnic store & 7 & Completely \\
\hline Specialty store & 5 & Partially \\
\hline
\end{tabular}

according to based on US Department of Agriculture dietary guidelines. The frequency of ethnic stores and specialty stores are shown in Table 1.

Therefore, in order to measure food availability and identifying food desert not only discount supermarket chains but also ethnic stores and specialty stores were assumed to be providers of healthy and affordable food options for residents of Englemount-Lawrence neighbourhood. The map of food desert results based on developed operational definition with inclusion of ethnic stores and specialty stores is shown in Figure 2.

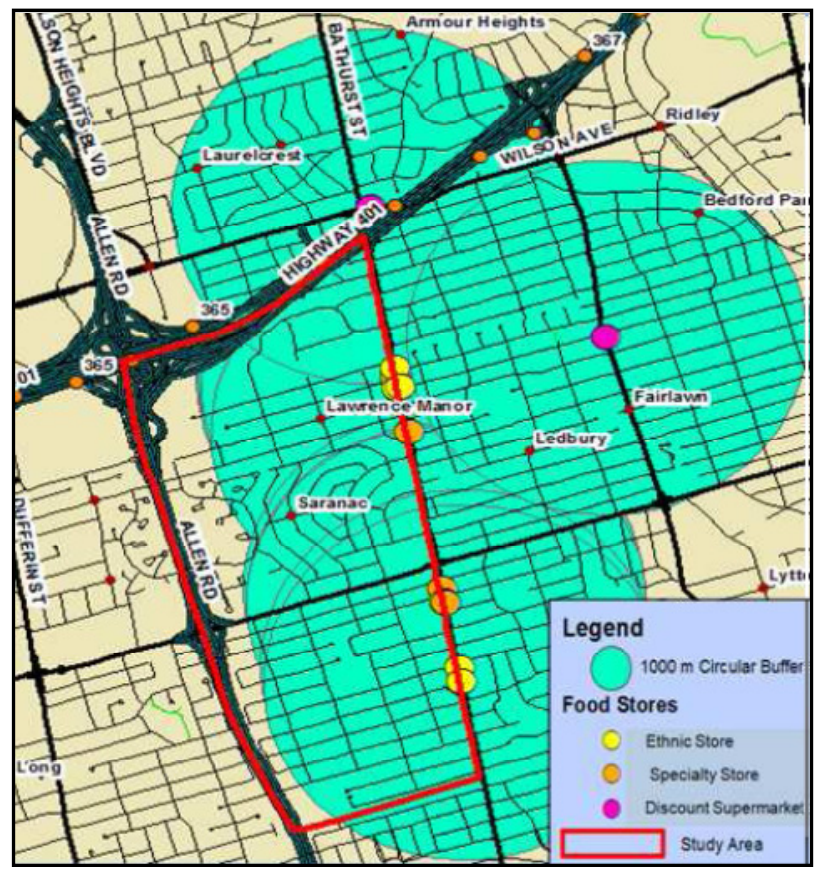

Figure 2: $\quad$ Food deserts: based on study operationalizing of food availability.

According to Figure 2, and in contrast with previous food desert studies, the revised food desert map indicated that only a small portion of the study area is identified as food desert due to the contributions of other food stores such as ethnic stores and specialty stores in providing healthy and affordable food options. Moreover, ethnic stores in the study area not only supply healthy and affordable food options but also provide culturally-accepted foods for the residents of other ethnicities. For example, according to The City of Toronto [19] 
Jewish and Filipino ethnic groups are the pre-dominant ethnicities in Englemount-Lawrence neighbourhood. Subsequently, out of seven identified ethnic stores in the study area, five of them are Jewish ethnic stores and the other two are Filipino ethnic stores. It should be noted that although specialty stores based on the nature of their business partially meet the 2010 USDA Dietary Guidelines but they can be complementary sources of healthy food options for the residents of Englemount-Lawrence neighbourhood.

The findings of this study are consistent with the results of Rose et al. [2] and Short et al. [18] which indicated that an area cannot be identified as a food desert based on the absence of supermarket and grocery stores when alternative sources of healthy and affordable food options are well-dispersed in the given area. In contrast, in a study by Nasr et al. [29] in the three neighbourhoods (DixonIslington, Scarborough village-Cliffcrest, and Thorncliffe-Flemingdon in the City of Toronto), the results indicated that ethnic stores and specialty stores in those three neighbourhoods cannot offset the relative lack of supermarkets in providing healthy and affordable food options because they are small in number and supply fewer healthy food options such as grains, milk, and meat products. However, the results of this study showed that ethnic stores and specialty stores not only enhance geographic access to healthy and affordable food options but also provide ethnic foods that meet cultural and religious preferences for immigrants such as Jewish and Filipino ethnicities in the Englemount-Lawrence neighbourhood. Koc and Welsh [30] pointed out that culturally accepted food by specialty stores and ethnic stores can improve food security among immigrants in the Toronto neighbourhoods.

\section{Conclusion}

As awareness of the link between the food environment, health-related and environmental consequences grows, practitioners and policy-makers need a better understanding of food deserts in urban neighbourhoods. They are often concerned and skeptical about the accuracy and validity of information that should be taken into account in guiding policy interventions, especially regarding complex issues that have achieved little consensus among researchers. In this study, by including alternative sources of healthy foods such as ethnic stores and specialty stores in measuring food availability we tried to produce more accurate and valid food desert results. The results of this study indicate that failure to use an inclusive set of healthy food stores and culturally acceptable food choices, in neighbourhood studies of food deserts can significantly alter the results in the study area and hence mislead food planners and policymakers in decisionmaking.

Although ethnic stores and specialty stores can be alternative sources of healthy food options, they may target specific segments of the local population. Further research is required to understand whether residents of other ethnicities face social and cultural barriers to purchase healthy food options from these food stores. 


\section{References}

[1] Cummins, S., and Macintyre, S. A. Systematic study of an urban foodscape: The price and availability of food in Greater Glasgow. Urban Studies, 39(11), pp. 2115-2130, 2002.

[2] Rose, D., Bodor, J. N., Swalm, C. M., Rice, J. C., Farley, T. A., and Hutchinson, P. L. Deserts in New Orleans? Illustrations of urban food access and implications for policy, 2009. http://www.npc.umich.edu/ news/events/food-access/rose_et_al.pdf

[3] Thomas, B. The relationship among household characteristics, geographic space, and food security in the Allen Neighborhood. http://www.allenneighborhoodcenter.org/wp-content/uploads/2010/01/2004 -Brian-Thomas-Study-of-ANC-Food-Security.pdf

[4] Lister, N. M. Placing Food: Toronto's Edible Landscape. http://www.ryerson.ca/foodsecurity/projects/urbandesign/Nina\%20Marie\% 20Lister\%20paper.pdf

[5] White, M. Food access and obesity. Obesity Reviews, 8 Supplement 1, pp. 99-107, 2007.

[6] Beaumont, J., Lang, T., Leather, S., and Mucklow, C. Report from the policy sub-group to the nutrition task force: low income project team of the [1] Department of health. Letchmore Heath, Watford: Institute of Grocery Distribution, 1995.

[7] Blanchard, T. C., and Lyson, T. Access to Low Cost Groceries in Nonmetropolitan Counties: Large Retailers and the Creation of Food Deserts. Paper Presented at the Measuring Rural Diversity Conference, Washington, DC, 2006.

[8] Hendrickson, D., Smith, C., and Eikenberry, N. Fruit and vegetable access in four low income food deserts communities in Minnesota. Agriculture and Human Values, (23), pp. 371-383, 2006.

[9] Gallaher, M. (2008). Food desert and food balance indicator fact sheet. http://www.marigallagher.com/site_media/dynamic/project_files/FdDesFd BalFactSheetMG_.pdf

[10] Trimarchi, M. What is a food desert? http://science.howstuffworks.com/ environmental/green-science/food-desert.htm

[11] United States Department of Agriculture (USDA). Food Desert Locator. www.ers.usda.gov/data/fooddesert/

[12] Larsen, K., and Gilliland, J. Mapping the evolution of 'food deserts' in a Canadian city: Supermarket accessibility in London, Ontario, 1961-2005. International Journal of Health Geographics, 7(16), pp. 1-16, 2008.

[13] Smoyer-Tomic, K., Spence, J. and Amrhein, C. Food deserts in the Prairies? Supermarket accessibility and neighborhood need in Edmonton, Canada, The Professional Geographer, 58(3), pp. 307-326, 2006.

[14] Mednath. Food Desert. http://medanth.wikispaces.com/Food+Desert

[15] Margheim, J. The Grocery of Eating Well. http://pdx.edu/ sites/www.pdx.edu.ims/files/media_assets/ims_mscape07atlas.pdf 
[16] Bitler, M., and Haider, S. J. An Economic View of Food Deserts in the United States. Journal of Policy Analysis and Management, pp. 153-176, 2011. http://srdc.msstate.edu/measuring/blanchard.pdf

[17] Ver Ploeg, M. Access to Affordable and Nutritious Food: Measuring and Understanding Food Deserts and Their Consequences. Economic Research Service. Report to Congress. http://www.ers.usda.gov/publications/ap lap036/ap036.pdf

[18] Short, Anne, Guthman, J., and Raskin. S. Food deserts, oases, or mirages? Journal of Planning Education and Research, 26 (3), pp. 352-64, 2007.

[19] City of Toronto. Priority Areas through the Neighbourhood Action Plan. http://www.toronto.ca/demographics/priorityareas.htm

[20] Chen, H. A Spatial Analysis of Discount Supermarkets and Their Implications for 'Food Deserts', (Master thesis). Ryerson University, Toronto, 2011.

[21] Martin Prosperity Institute. Food deserts and priority neighbourhoods in Toronto. http://martinprosperity.org/2010/06/15/food-deserts-and-priority neighbourhoods-in-toronto/

[22] Toronto Community Health Profile. Englemount-Lawrence Profile: Sociodemographic.

http://torontohealthprofiles.ca/a_documents/HPD_neighb_data/HPD_neigh b_SocDem_data/HPD_neighb_SocDem_2006/HPD_neighb_SocDem_200 6_32.pdf

[23] Statistics Canada. North American Industry Classification System, Canada 2012. Ottawa: Statistics Canada, Standards Division. http://www.statcan.gc. ca/pub/12-501-x/12-501-x2012001-eng.pdf

[24] Crouch, C. Community Food Resources Report: Assessment of Access. http://www.phxrevitalization.org/ccsqlp/foodresources/CCS\%20Communit y\%20Food\%20Resources\%20Report_Final.pdf

[25] United States Department of Agriculture. (USDA). Dietary Guidelines for Americans. http://www.cnpp.usda.gov/DietaryGuidelines.htm

[26] Thornton, L.E., Pearce, J.R., and Kavanagh, A.M. Using Geographic Information Systems (GIS) to assess the role of the built environment in influencing obesity: a glossary, International Journal of Behavioral Nutrition and Physical Activity, 8(71), pp. 1-9, 2011.

[27] Apparicio, P., Marie-Soleil, C., and Shearmur, R. The case of Montréal's missing food deserts: Evaluation of accessibility to food supermarkets. International Journal of Health Geographics 6(4), pp 1-13, 2007.

[28] DMTI Spatial Inc. CanMap Route Logistics: Network Analyst. Version 2010.3. Markham, Ontario, 2010.

[29] Nasr, S., Polsky, J., Patychuk, D., and Sopher, L. Food Mapping and Access to Healthy Food/Food Security. http://www.intohealth.ca/wpcontent /uploads/Health_Action_Areas/Food_Mapping_Healthy_Eating_Food_Sec urity.pdf

[30] Koc, M., and Welsh, J. Food, Identity and Immigrant Experience. Canadian Diversity, 1(1), pp. 46-48, 2002. 